URSO, Graziela Schneider. A revolução das mulheres: emancipação feminina na Rússia soviética: artigos, atas, panfletos, ensaios. São Paulo: Boitempo, 2017. 276 p.

\title{
Sobre conquistas revolucionárias
}

\section{On revolutionary achievements}

Jorge Luiz Zaluski ${ }^{1}$

A aproximação do centenário da Revolução Russa contribuiu para intensificar o número de produções que problematizam tanto a revolução como outras questões que circunscrevem a temática. No Brasil, publicações de pesquisas com novas abordagens, fontes ou até mesmo traduções inéditas do russo para o português nos fornecem subsídios para a compreensão tanto da revolução como das relações socioculturais pré e pós-revolução. Portanto, a Revolução Russa não se restringe apenas aos acontecimentos de 1917, os quais são consequências e abertura de novas temporalidades, relações sociais, políticas e culturais, dentre outras que possibilitam que o/a historiador/a amplie seu campo de investigação. Tal como destaca François Dosse, o acontecimento deve ser compreendido "como resultado e como começo, como desfecho e como abertura de possíveis" (DOSSE, 2013, p. 6).

É com esse objetivo que o livro A revolução das mulheres: emancipação feminina na Rússia soviética insere-se no campo da pesquisa histórica. Organizada por Graziela Schneider Urso - tradutora, graduada em russo e português pela Universidade de São Paulo, mestra e doutora em literatura e cultura russa pela mesma instituição - e desenvolvida com o trabalho coletivo de outras quinze tradutoras, a obra possui textos produzidos por mulheres que ocuparam posições distintas na Rússia e posterior União Soviética, no início do século XX. Traduzidos pela primeira vez ao português, esses escritos foram reunidos por Schneider Urso e publicados pela editora Boitempo em 2017.

Com diferentes profissões voltadas à atuação política, onze mulheres fornecem os escritos que compõem a publicação resenhada. Além da apresentação feita por Schneider Urso, o livro possui 42 textos, entre ensaios, panfletos, atas, artigos publicados em jornais e revistas ou proferidos em conferências, que demostram a militância das mulheres. Sem divisão por capítulos, foi organizado com base na produção das autoras, sem apresentar uma

\footnotetext{
${ }^{1}$ Doutorando pelo Programa de Pós-Graduação em História da Universidade do Estado de Santa Catarina PPGH-UDESC. Bolsista do Programa de Bolsas de Monitoria de Pós-Graduação - PROMOP. E-mail: jorgezaluski@hotmail.com
} 
ordem cronológica. Possui também breves biografias de cada autora, as quais antecedem as subdivisões e são ilustradas majoritariamente por retratos das autoras.

A luta das mulheres antecedeu a Revolução Russa, tomou proporções maiores e as mobilizações se intensificaram na Revolução de Fevereiro. Correspondentes a produções do início do século $\mathrm{XX}$, os escritos permitem perceber a configuração, pluralidade das reinvindicações e ativismo de diferentes grupos de mulheres em diversas cidades. Junto à investigação das relações políticas, sociais e econômicas, tendo por base dados da saúde, trabalho e escola, e outros documentos como cartas e legislação do período, as análises contribuem para romper com visões generalistas construídas sobre a Revolução Russa ao longo do tempo. De modo bastante enriquecedor, o livro colabora para a investigação sobre o período e disponibiliza novas fontes, assim como instiga o/a leitor/a ao demonstrar que algumas pautas do movimento feminista russo foram alcançadas no início do século passado, dentre elas a descriminalização do aborto e a criminalização da homofobia. No Brasil do tempo presente, por exemplo, a primeira questão tramita de forma lenta no sistema judiciário; com relação à segunda, ainda não existe lei que trate a homofobia como crime.

Mesmo adiantando que o movimento feminista russo e soviético possui peculiaridades em comparação ao restante do mundo, um dos pontos mais ricos da publicação consiste em fazer com que o/a leitor/a realize constantes análises sobre as pautas do movimento. Observação essa que corresponde aos questionamentos realizados por Schneider Urso logo na apresentação do livro, quando interroga: "existiu apenas um "feminismo" russo e soviético?" (URSO, 2017, p. 13).

Parte da resposta pode ser encontrada logo nos primeiros textos. Anna Andréieva Kalmánovitch (s.d) inaugura a obra demostrando que a situação econômica das russas contribuiu para impulsioná-las à luta por direitos. Como militante em busca da causa chamada de "questão feminina", realizou várias reinvindicações por meio de palestras, conferências e publicações nas revistas Soiúz e Jénski Viéstnik. Considerada feminista radical, suas declarações demostram que a situação das mulheres contribuiu para desenvolver uma consciência em busca da sobrevivência e por melhores condições de vida. Dentre elas, a autora aponta a necessidade de romper com ações que visam impedir o acesso das mulheres à educação. Mesmo com a existência de engenheiras, matemáticas, médicas, dentre outras profissionais, currículos sexistas e a não valorização profissional não permitem uma educação igualitária. Para a autora, casos isolados não podem ser equiparados à existência de oportunidades. Diante disso, ao afirmar que o movimento feminista não é partidário, alega a 
necessidade das russas participarem da política sendo eleitoras e eleitas para que seja possível criar leis favoráveis para as mulheres. Pois, em relação aos homens, Kalmánovitch em "O movimento feminista e a relação dos partidos com ele" (1908), afirma que é "contra a ideia de que nós mulheres devemos esperar deles a liberdade.” (KALMÁNOVITCH, In URSO, 2017. p. 38)

A historiadora Elena Aleksándrovna Kuvchínskaia (1874-1928) e a jornalista Konkórdia Nikoláievna Samóilova (1976-1921), mesmo com produções em períodos distintos - a primeira com escritos de 1908 e a segunda com publicação de 1918, possuem semelhanças em suas reinvindicações, principalmente sobre a atuação do governo frente às mobilizações. Samóilova, de modo bastante crítico, destaca que a Revolução de Fevereiro só foi possível devido às mulheres. Contudo, posteriormente a fevereiro de 1917 as reinvindicações não foram atendidas como esperado e, em "O que a Grande Revolução de Outubro deu aos operários e camponeses" (1918) segundo a autora, "receberam somente míseras migalhas que caíram da mesa dos senhores burgueses e capitalistas." (SAMÓILOVA, In URSO, 2017, p. 257)

Diante das críticas e observações sobre as revoluções de fevereiro e outubro, assim como Samóilova, Liubov Iákovlena Guriévitch (1866-1940), jornalista e escritora, no texto "Sobre a questão do sufrágio feminino na sociedade russa, nos ziémstvo e nas cidade" (1907) e Olga Andréivna Chapír (185-1916), escritora de origem camponesa, em "Ideais do Futuro" (1908), tecem considerações importantes sobre as violências sofridas pelas mulheres e abrem espaço para questionar posicionamentos generalizantes, tais como o de que a revolução foi feita apenas por camponeses/as e operários/as. Para elas, o movimento feminista existiu junto à política, literatura, medicina, educação, dentre os mais diversos setores, e partiu da necessidade de romper com as desigualdades e violências cometidas contra as mulheres e tomou proporções maiores ao aliar-se a mulheres que ocupavam posições diferentes burguesas, por exemplo - bem como a homens que lutavam por melhores salários.

Passados dez anos Inessa Fiódorovna Armand (1874-1920), por exemplo, apresenta posicionamento bastante distinto. Política e com grande atuação em diferentes mobilizações, comandante do departamento de mulheres do Comitê Central do Partido Comunista, e cujas afirmações apontam para o fato de que essas supostas alianças não deram certo. Com severas críticas ao capitalismo, Armand defende a ideia de que as mulheres pertencentes à burguesia estavam em uma situação privilegiada e por isso tiveram maior espaço na política. A autora, em "A trabalhadora e o Congresso de Toda a Rússia" (1917) defende que as mulheres 
burguesas apenas buscavam votos oriundos das mulheres pobres e que eram "tão exploradoras, tão inimigas do movimento trabalhador e da revolução operária quanto os homens burgueses." (ARMAND, In URSO, 2017, p, 227).

As diferentes experiências vivenciadas e transcritas nos textos que compõem o livro permitem perceber a negociação ativa dessas mulheres nos partidos políticos, relações de trabalho, espaço doméstico, dentre outros momentos e situações em que tanto a liberdade como a oportunidade de melhores condições de vida eram confrontadas. De um modo geral, todas as autoras apresentam constantes releituras do passado em busca de um futuro melhor. Como lembra Reinhart Koselleck, um horizonte de expectativa construído com base nas experiências. Contudo, esse desejo por um futuro melhor não consistiu apenas devido ao presente indesejado. Tanto Chapír como Ekaterina Dmítrievna Kuskova (1869-1958) e Ariadna Vladímirovna Tirkóva-Williams (1869-1962) apresentam em suas obras um balanço sobre as conquistas e resultados dos congressos das mulheres já realizados. Ao olharem para o passado, destacam a existência de avanços e retrocessos obtidos por meio de alianças entre diferentes grupos de mulheres e homens. Chapír, por exemplo, em 1908 afirmou que o movimento pouco avançou em relação à maternidade. Mesmo com posição conservadora em que reafirma a existência de uma "natureza feminina" relacionadas à força e ao amor, a autora afirmou que, "a mãe não possui o direito à maternidade livre e é obrigada a uma maternidade coercitiva dentro da indissolubilidade do casamento." (CHAPÍR, In URSO, 2017, p. 45)

A maternidade foi alvo de constantes reinvindicações, como assunto de saúde pública; as russas se manifestaram em busca da autonomia do próprio corpo e a descriminalização do aborto, conquistado no ano de 1920. As condições precárias vivenciadas por muitas mulheres contribuíram para outros problemas sociais como a prostituição - vista como uma fuga para muitas mulheres não morrerem de fome. Ser mãe como escolha foi apresentado como uma condição de sobrevivência. Maria Ivánovna Pokróvskaia (1852- s.d.), médica, com escritos entre os anos de 1908 e 1914, sob uma perspectiva de estrutura de classe fornece análise bastante atenta de como a legislação da época não atendeu as necessidades das mulheres. Pokróvskaia parte da percepção de que as leis russas sobre casamento e relações sexuais atuaram como marcadores sociais que serviam para limitar a ação das mulheres em condições de exploração, violência e demais situações em que a liberdade não existia. Com base na interpretação de Pokróvskaia, a permissão de relações sexuais para as mulheres a partir dos 14 anos e a proibição do casamento até completar 16 anos contribuíram para a manutenção da prostituição e a gravidez indesejada. Com o trabalho das mulheres aceito apenas com a 
autorização do marido e acompanhado de passaporte que provasse tal permissão, muitas jovens buscaram a prostituição como forma de sustentar a si mesmas e contribuir na renda familiar. Diante da pobreza e situações onde os homens possuíam liberdade, autonomia e demais situações favoráveis, em "Lei e vida" (1914) Pokróvskaia afirma que "entre o casamento e o consentimento do ato sexual há um intervalo de dois anos, ao longo dos quais a menina pode estabelecer relações extraconjugais e entregar-se à prostituição, enquanto aos homens é permitido aproveitar-se delas impunemente." (POKRÓVSKAIA, In URSO, 2017, p. 68)

Posicionamento próximo aos de Nadiéjda Kostantínovna Krúpskaia (1869-1939), pedagoga com grande participação nas decisões políticas do Partido Operário SocialDemocrata, e cujas reinvindicações e conquistas obtidas não devem ser lembradas apenas por ela ter sido esposa de Vladímir Ilitch Ulianov (Lenin). Com textos publicados entre 1908 e 1935, é possível perceber as influências e posições em apoio a Lenin. Contudo, Krúpskaia mobilizou-se em diferentes momentos em busca de uma sociedade mais igualitária. A maternidade como escolha estava entre suas pautas. Krúpskaia defendeu também que a educação escolar e familiar devem presar pela igualdade entre homens e mulheres. Tal posição levou a questionar as próprias feministas ao publicar um artigo em revista intitulado: “Deve-se ensinar 'coisas de mulher' aos meninos?” (1909) (KRÚPSKAIA, In URSO 2017, p. 88)

Sabe-se que Karl Marx teve forte influência em vários escritos e mobilizações russas e soviéticas. A escritora e política Aleksandra Mikháilovna Kollontai (1872-1952), por exemplo, é uma das autoras que se apoia nos manuscritos de Marx. Contudo, os escritos destacados na antologia ora reduzem a participação das mulheres em total apoio e privilégio às ações de Lenin, ora valorizam o protagonismo das mulheres que lutaram pela "questão feminina". A obra Mulher, Estado e revolução, de Wendy Goldman, publicada no Brasil em 2014, utiliza alguns documentos produzidos por Kollontai. Agora, com parte dos próprios manuscritos traduzidos para o português, é possível ampliar e construir novas investigações historiográficas. Através dos textos da autora é possível perceber a configuração das relações sociais da Rússia durante a Primeira Guerra Mundial e a guerra civil russa. Em, "Da história do movimento das trabalhadoras na Rússia" (1909), ao destacar as mobilizações das camponesas, a autora enfatiza a necessidade de lembrar das mulheres que lutaram por direitos. Para Kollontai, “armadas com rastilhos, forquilhas e vassouras, elas expulsaram os militares 
das aldeias e povoados. Protestavam a sua maneira contra o fardo insuportável da guerra." (KOLLONTAI, In URSO, 2017, p. 198).

O livro organizado por Schneider Urso é de agradável leitura e de grande valia para a compreensão das diferentes mobilizações das mulheres russas e soviéticas. Com diferentes reinvindicações feministas, a revolução das mulheres teve um caráter duplo, levantou-se contra todas as formas de opressão das quais sofriam e foi uma das responsáveis pela Revolução Russa. Conforme Rachel Soihet, as reivindicações dessas mulheres influenciaram o movimento feminista brasileiro. Com os textos disponíveis em português, torna-se possível aprofundar os estudos sobre a Revolução Russa, o movimento de mulheres e feminista russo e soviético, assim como construir novas expectativas em busca de uma sociedade livre de desigualdades e violência contra as mulheres.

\section{Referências}

DOSSE, François. O renascimento do acontecimento: um desafio para o historiador: entre Esfinge e Fênix. São Paulo: Editora Unesp, 2013.

GOLDMAN, Wendy. Mulher, Estado e revolução. São Paulo: Boitempo; Iskra, 2014.

KOSELLECK, Reinhart. Estratos do tempo: estudos sobre história. Rio de Janeiro: Contraponto: PUC-Rio, 2014.

SOIHET, Rachel. Movimento de mulheres. In: PEDRO, Joana Maria. (org). Nova história das mulheres no Brasil. São Paulo: Contexto, 2013. p. 218-237. 